\title{
A HISTÓRIA DA ÁFRICA: UMA LEITURA DO CURRÍCULO ESCOLAR DO ESTADO DE SÃO PAULO
}

\author{
Carlos Eduardo Rodrigues
}

Universidade Estadual de Maringá-UEM, Especialização em História e Movimentos Sociais (EAD), Maringá-PR, E-mail: acruzada@hotmail.com

\section{RESUMO}

O tema a ser desenvolvido é o modo como à história do continente africano é ensinado no currículo de história do Estado de São Paulo, o objetivo é compreender a organização dos conteúdos e a proposta didática existente em dois materiais disponibilizados a alunos e professores: o Caderno do Aluno e o Caderno do Professor. Através de uma metodologia que revisite a bibliografia publicada em mídias impressa e digital acompanhada da análise teórica do currículo, documento oficial que regulamenta este campo de ensino em toda a escolar público, procuro debater questões que envolvem o ensino e a representação da África e dos africanos. Esperamos que a pesquisa contribua para o desenvolvimento sociocultural e humanístico dos alunos visando compreender melhorar a percepção deles sobre a África.

Palavras chave: Currículo de História, Educação, Ensino de História, História da África, Movimentos Sociais.

\section{THE HISTORY OF AFRICA: A READING OF THE SCHOOL CURRICULUM OF THE STATE OF SÃO PAULO}

\section{ABSTRACT}

The theme to be developed is the way in which the history of the African continent is taught in the history curriculum of the State of São Paulo, the objective is to understand the organization of the contents and the didactic proposal existing in two materials available to students and teachers: the book of the student and the book of teacher's. Through a methodology that revisits the bibliography published in print and digital media accompanied by the theoretical analysis of the curriculum, official document that regulates this field of education throughout the public school, I try to discuss issues that involve the teaching and representation of Africa and the africans. We hope that the research contributes to the socio-cultural and humanistic development of the students in order to understand how to improve their perception of Africa. Key Words: Curriculum of History, Education, History Teaching, History of Africa, Social Movements.

\section{INTRODUÇÃO}

Nas últimas décadas o ensino de História sofreu inúmeras transformações com a entrada das leis $10.639 / 2003$ e $11.645 / 2008$ que instituíram a obrigatoriedade do ensino de História e Cultura Afro-brasileira e Indígena na rede de ensino pública e privada. Fruto de um longo processo de luta dos Movimentos Sociais as leis modificaram a forma de atuação dos professores em sala de aula, desde então testemunhamos uma corrida na área de ensino para atender as novas demandas educacionais.

A África em sala de aula ainda é um problema para a maioria dos professores, boa parte dos docentes não teve em sua formação disciplinas específicas sobre o tema o que gera dificuldades para entender a dinâmica social africana. Esta deficiência está alinhada a nossa formação eurocêntrica, da qual crença no modelo de desenvolvimento da Europa Ocidental como uma fatalidade "desejável" por todos os povos atua como ideologia dominante, e que destaca o protagonismo europeu na formação do mundo moderno através das produções culturais que exaltam o estilo de vida do ocidente.

O eurocentrismo está nas produções culturais e na mídia que apresentam (des) informações sobre a África ao ressaltar as crises humanitárias como sendo exclusivo do continente, no ensino de história ele se impõem na estrutura curricular, centralizado na explicação europeia do mundo e dividido em dois blocos. O primeiro trata da História do Brasil narrada a partir da chegada dos portugueses e 
suas instituições políticas, os grandes eventos e os personagens históricos giram em torno do protagonismo ocidental, e mesmo com as leis $10.639 / 2003$ e 11.645/2008 a história do negro e do índio ainda são contadas do ponto de vista do colonizador. O segundo trata da História Geral que é uma síntese da História da Europa agrupada em três nações: a Inglaterra devido a Revolução Industrial, a França por causa da Revolução Francesa e Portugal em virtude da colonização do Brasil. Os demais países aparecem de forma esporádica, como a Alemanha Nazista e a Itália do Renascimento.

A centralidade na história da Europa provoca aquilo que a escritora nigeriana Chimamanda Adichie chamou em sua palestra para o Technology; Entertainment; Design (TED) de "O perigo de uma História única" (ADICHIE, 2009), nela a escritora conta parte de sua trajetória de vida para explicar que não existe apenas uma história sobre um lugar e os problemas de insistirmos em relatar somente um lado não torna a história mentirosa e sim incompleta. No caso da história da África a condução dos conteúdos é feita a partir da expansão europeia o que gera nos alunos uma visão estereotipada e quando muito superficial resultando na desqualificação da história dos africanos e afro-brasileiros.

\section{METODOLOGIA}

Partimos de um levantamento bibliográfico de materiais impresso e digital cuja área de conhecimento é os Estudos Africanos, eixo temático dedicado à história da África e das diásporas africana. Objetiva-se compreender a interação entre a África e o currículo escolar para melhorar a qualidade de ensino e prepara dos alunos para o exercício da cidadania. Como fonte de pesquisa escolhemos o currículo escolar do Estado de São Paulo que é aplicado a toda rede de ensino. Fruto da escolarização em massa onde houve a necessidade de padronização do conhecimento a ser ensinado o currículo escolar é elaborado por toda a equipe pedagógica e atua como norteador das práticas educativas, além de ser um documento adaptável às habilidades e competência dos alunos (DAMASCENO; MESQUITA, 2015).

O currículo do Estado de São Paulo atua como proposta pedagógica que integra as Orientações para a Gestão Curricular da Escola, documento dirigido as unidades escolares para auxiliar os agentes educacionais na organização burocrática e pedagógica do colégio. Para a execução do currículo alunos e professores contam com os Cadernos do Aluno e os Cadernos do Professor. Chamados usualmente de "caderninhos" ou "apostilas" estes materiais fazem parte de uma política educacional implantada em 2008 como forma de concretizar a proposta curricular do Estado que está fundamentada nos Parâmetros Curriculares Nacionais (PCNs) e demais documentos que norteiam a educação brasileira. Sendo um material de apoio ao currículo os Cadernos do Aluno e do Professor fazem parte do programa São Paulo Faz Escola (SPFE) e estão organizados da seguinte maneira:

No primeiro semestre letivo, entre fevereiro e junho, o professor precisa desenvolver o Caderno número 1 . No segundo semestre, entre agosto e dezembro, é desenvolvido o Caderno número 2. Cada Caderno é composto por 8 situações de aprendizagens que abordam um eixo temático da disciplina e conta com um conjunto de habilidades e competências a serem desenvolvidas. Ao final do ano letivo, quando se conclui as 16 situações de aprendizagens, espera-se que o aluno atinja o mínimo de conhecimento de acordo com sua idade e série. Entre o Caderno do Aluno e do Professor há diferenças, no material entregue aos docentes há uma série de textos, atividades, métodos, sugestões e estratégias de estudos interdisciplinares para serem aplicados em sala de aula. É importante ressaltar que o foco dos "caderninhos" são as competência e habilidades necessárias para os alunos resolverem as questões do Exame Nacional do Ensino Médio (ENEM) e do Sistema de Avaliação do Rendimento Escolar do Estado de São Paulo (SARESP) e não para a vida em sociedade.

\section{RESULTADOS}

Os resultados atingidos até agora possibilitou compreender que os Cadernos do Aluno e do Professor atuam como mecanismos institucionais de centralização dos conteúdos abordados em sala de aula e foram desenvolvidos para combater a má qualidade do ensino, a evasão escolar e o analfabetismo funcional. Diferentemente do livro didático, cuja elaboração leva em consideração todo o território nacional, os "caderninhos" representam o projeto educacional do Estado de São Paulo, o que dificulta a adequação de alunos proveniente de outros Estados. Além disso, os "caderninhos" 
acabam limitando a autonomia do professor enquanto mediador do conhecimento, já que neles estão as orientações metodológicas e pedagógicas a serem aplicadas em sala presumindo que o professor não possui qualificação adequada para ensinar.

Outro ponto que observamos é a relação dos "caderninhos" e a evolução salarial dos docentes via bonificação. Anualmente os alunos 1a, 3a, $5 \underline{a}$, 7a e 9a ano do Ensino Fundamental e os alunos do 3a ano do Ensino Médio realizem o SARESP, uma prova objetiva composta por Matemática e Língua Portuguesa. O desempenho da escola é calculado pelo Índice de Desenvolvimento da Educação do Estado de São Paulo (Idesp) e de acordo com a performance dos alunos os docentes que atuaram na escola durante $o$ ano de realização da avaliação recebem a bonificação salarial. Esse incentivo salarial visa à melhora do rendimento escolar estimulando o docente a trabalhar mais para conseguir a bonificação, no entanto, o efeito negativo desta prática é que a preocupação exacerbada dos professores em cumprir todos os "caderninhos" faz com que evitam atividades educacionais extras ou temas que não estão presentes nessas "apostilas".

A centralização em torno dos "caderninhos" leva a desconsideração das particularidades de cada região e de cada escola, ao padronizar o que é ensinado o Estado não se atenta para os problemas enfrentados pela comunidade escolar e isso acaba provocando defasagens de ensino entre as escolas ao tratar realidades sociais distintas como iguais. Os cadernos são o espelho do currículo escolar do qual o professor tem o dever de cumpri-lo ao longo do ano letivo, concluir os "caderninhos" é o equivalente a satisfazer a ordem imposta pelo Estado, sendo assim, os professores focam seu trabalho pedagógico na conclusão de grande parte das atividades do Caderno do Aluno para evitar constrangimentos administrativos frente a seus superiores, fazendo do processo de ensino e aprendizagem algo secundário durante a prática de ensino.

Outro avanço foi a percepção de que o currículo trabalha de modo conjunto a África e a escravidão no Brasil, durante a análise para o Ensino Fundamental II observamos que o tema África aparece só uma vez sem estar relacionado com o tráfico e a escravidão no Brasil. É no volume 1 do "caderninho" do 60 ano na situação de aprendizagem 7 intitulada "África, o berço da humanidade" onde os conteúdos e temas a serem desenvolvidos são a "Pré-história africana; sociedades coletoras; desenvolvimento da agricultura; diferentes artefatos pré-históricos".

Nos "caderninhos" do 7ㅇ e 8ㅇ ano a África e a escravidão no Brasil estão juntas com predomínio do tema da escravidão durante as abordagens. Para o 70 ano o volume 2 discute o "Quilombo: um símbolo de resistência à escravidão" (situação de aprendizagem 5) que traz como conteúdos e temas os "Quilombos; resistência africana; escravidão; engenhos coloniais; bandeirantes; Palmares; Zumbi; Ambrósio; identidade", já para o 8o ano o volume 2 inicia os estudos com o enunciado "A Revolta dos Malês" (situação de aprendizagem 1) dos quais os conteúdos e temas dizem respeito a "revolta; rebelião; escravismo; islamismo; muçulmano; liberdade religiosa; Guarda Nacional", na situação de aprendizagem 6 do mesmo volume o capítulo "O processo de abolição da escravidão" traz como conteúdos e temas o "trabalho escravo; trabalho livre; abolição; quilombo". Nessas três situações de aprendizagem a África fica com pano de fundo para as questões da resistência negra ao processo de escravização no Brasil.

A necessidade de gerar conhecimentos para a valorização do passado dos povos africanos e afro-brasileiros é um meio de enriquecermos o debate público sobre o futuro do nosso Estado-Nação. A população negra atua diretamente no desenvolvimento do país, mas sua trajetória é desconhecida do público. A rasa menção aos movimentos sociais na África reflete nossa formação eurocêntrica que valoriza as revoluções europeias, em especial os caso inglês, francês e russo. Esse fato é visível nos conteúdos do 9o ano onde a África aparece em duas situações de aprendizagem.

No volume 1 na situação de aprendizagem 1 "Imperialismo e Neocolonialismo no século XIX" os conteúdos e temas abordados são "Segunda Revolução Industrial; Imperialismo, Neocolonialismo; Capitalismo Financeiro, Capitalismo Monopolista; Darwinismo Social; Conferência de Berlim", aqui as atividades são direcionadas ao colonialismo na África e na Ásia durante o século XIX. Já no volume 2 na situação de aprendizagem 1 "Os dez princípios da Conferência de Bandung" os conteúdos e temas são o "nacionalismo; autodeterminação; colonialismo; descolonização; segregação racial; discriminação racial", neste ponto as atividades 
propõem 0 debate sobre as independências africanas e asiáticas.

Ambas as situações de aprendizagem abordam a colonização e independência da África subordinando-os a história da Europa, a experiência africana é decorrência da expansão do capitalismo Industrial e do enfraquecimento das potencias colônias após a Segunda Guerra Mundial. Em nenhum momento as experiências africanas são interpeladas de forma autônoma.

\section{DISCUSSÃO}

Pensar em procedimentos de ensino que valorizem a diversidade africana não é simples dado que requer do professor um olhar menos eurocêntrico para o continente. A estrutura didática dos currículos escolares de Histórica simboliza a síntese da expansão europeia pelo mundo, se levarmos em consideração a afirmação de Bonzatto (2011, p. 30) de que "os livros didáticos não podem ser entendido apenas como instrumentos pedagógicos, também são produtos de grupos sociais que procuram, por intermédio deles, perpetuar suas identidades, seus valores, suas tradições", um olhar crítico sobre o currículo escolar e os "caderninhos" é de extrema urgência uma vez que alerta os docentes sobre "O perigo de uma História única".

Um problema teórico quando falamos sobre África em Sala de aula é: a história da África é a mesma que a história do negro no Brasil? A história do negro no Brasil se resume a escravidão? A história da escravidão sintetiza a história da África? De início estas perguntas parecem esporádicas, mas dizem respeito às percepções que boa parte dos educadores tem sobre a temática africana. São conteúdos distintos a história da África e a história do negro do Brasil e embora esteja vinculado estudar um não necessariamente significa compreender $o$ outro.

Ensinar aos alunos o processo de escravização do negro no Brasil não significa explicar a história da África, embora a escravidão faça parte da história de ambas as regiões não podem resumir a história e a riqueza do continente africano a um único fato histórico. A meu ver, a escravização do negro no Brasil é assunto da história do Brasil e não da história da África, aqui deveríamos ensinar sobre a construção das grandes civilizações africanas ao longo da Idade Antiga e da Idade Média, a formação política das sociedades africanas em contato com os muçulmanos e os europeus na
Idade Moderna, as relações socioeconômicas, a resistência ao processo de partilha e as lutas de libertação durante a Idade Contemporânea, e principalmente a contribuição da África para o desenvolvimento da ciência e da tecnologia mundo a fora.

Segundo Santos (2012, p. 48) "o conhecimento e a origem da população afro no Brasil são escassos, restringindo-se somente ao tráfico negreiro, deixando de lado a contribuição linguística, literária, cultural, econômica, social e política". Ao narrarmos à história da África e do povo negro no Brasil como sendo uma síntese do trafico negreiro e da escravidão reforçamos o imaginário do africano bárbaro e violento por natureza que precisa urgentemente ser salvo de si mesmo seja pela fé ou pela ciência. Ao aceitarmos que a história da África e do negro podem ser resumida ao processo de escravização estamos gerando efeitos nocivos na sociedade, se um aluno aprende desde os 11 anos de idade que na África só tem escravos quando adulto esse tipo de (des) informação será replicado no âmbito social e com isso corremos o risco de produzirmos pessoas intolerantes que coloquem em risco a nossa frágil democracia.

Diariamente exemplos de intolerância testam nossa crença no mundo sem racismo, basta ver as diversas declarações xenofóbicas que foram expostas nas redes sociais aos refugiados que chegam ao Brasil e em outras partes do mundo Ocidental, ou a visão pejorativa e simplista que os mesmos têm sobre as revoltas, as guerras e as disputas políticas em solo africano. Atualmente os meios de comunicação apresentam estes assuntos, mas o debate acerca do que realmente está acontecendo é pouco aprofundo. Tal superficialidade é levada para a sala de aula pelos alunos que muitas vezes não compreendem o que está acontecendo e reproduzem as (des) informações que recebem no cotidiano, algo semelhante ocorre entre os professores que por não terem conhecimentos teóricos para desenvolver o tema acabam reafirmando a postura da mídia.

As superficialidades dos meios de comunicação refletem negativamente na formação dos alunos, desenvolver métodos de ensino e aprendizagem que expliquem a realidade africana como as revoltas, as rebeliões e as revoluções que constantemente acontecem no continente e são apresentadas nos noticiários não é algo simples, pois cobra do professor dedicação e empenho para sintetizar informações 
que não estão presente nos "caderninhos". Sendo assim, é de suma importância melhorar nossa compreensão sobre a África para entendêla dentro de uma dinâmica própria, questionando os modelos explicativos que apontam para a Europa como definidora das ações politicas. Com isso levamos ao público novos conhecimentos sobre a África que servem de suporte teórico para combater o eurocentrismo e o racismo que paira sobre nossa sociedade.

\section{CONCLUSÃO}

As avalições sobre o currículo e os "caderninhos" desenvolvido pela SPFE apresentam narrativas históricas que tem a "preocupação em enfatizar aspectos da História da África que guardem alguma semelhança com aspectos da História do Ocidente", quando muito ressaltam um caráter instrumental do mesmo que surge em função da "História do Brasil e não como um objeto historiográfico em si mesmo", por isso é comum nos materiais didáticos à concentração de itens programáticos sobre os afro-brasileiros no período de vigência do tráfico negreiro no Atlântico (GONÇALVES, 2014, p. 9697). Esta forma de descrever a História excluem o protagonismo do povo africano e por isso a importância em revisitar o que está sendo ensinado nas escolas para melhorar a nossa compreensão do passado.

Revisitar e reavaliar o ensino de história faz parte de um exercício intelectual amplo onde o suporte teórico é encontrado nos estudos sobre a pós-modernidade, que permitiu o reconhecimento da multiplicidade e da heterogeneidade das sociedades no planeta o que causou a reflexões sobre o papel da Europa na construção do mundo moderno, diversos centros de pesquisas em Ciências Humanas entendem que o ocidente não detém mais o monopólio das transformações socioculturais, políticas e econômicas, hoje os países periféricos elaboram sua própria interpretação do mundo e lutam para manter a autonomia nacional frente à globalização. Essa caraterística trazida pela pósmodernidade nos leva a refletir sobre conceitos, métodos e teorias sociais e instiga o pesquisador a novos desafios (PIETERSE, 1996).

O estudo do currículo escolar é parte do ofício do historiador, somente assim conseguiremos gerar uma sociedade aonde todos são representados. Os caminhos para conhecer uma história da África e do negro no Brasil é longo, mas se faz necessário porque atua como instrumento de luta contra o racismo e a exclusão social, cabe ao educador e a escola desenvolver mecanismos didáticos e pedagógicos que contemplam a diversidade sociocultural. 0 enfrentamento a desinformação, aos preconceitos e ao racismo são problemas da nossa época e o professor precisa agir com agente transformador visto que é sua função levar aos estudantes algo muito além do senso comum.

\section{REFERÊNCIAS}

ADICHIE, C. O perigo de uma História única.

Palestra gravada em vídeo para Technology; Entertainment; Design (TED) em julho de 2009. Disponível em:

http://www.ted.com/talks/lang/pt/chimamanda_ adichie_the_danger_of_a_single_story.html.

Acesso em: 09 set. 2018.

BONZATTO, E. A.. Aspectos da História da África da Diáspora Africana e da Escravidão sob a perspectiva do poder eurocêntrico. São PauloSP: Íconi, 2011.

DAMASCENO, A. M. P.; MESQUITA, M. E. P. dos S. Contribuições norteadoras do currículo no contexto escolar. In: CONGRESSO NACIONAL DE EDUCAÇÃO -EDUCERE, 12., 2015. Curitiba. Anais [...]. Curitiba,PR: PUCPR, 2015.

GONÇALVES, J. H. R. Das resistências ao ensino escolar de história da África: algumas considerações. História \& Ensino, Londrina, v. 20, n. 1, p. 83-100, jan./jun. 2014.

PIETERSE, E. Reflexões sobre os movimentos sociais urbanos na África do sul numa "era de globalização". Revista História Social, Campinas,SP, n. 3, , p. 173-194, 1996.

SANTOS, J. F. dos. Relações Brasil e África para além da escravidão: Ensino da História Afrobrasileira e Africana numa perspectiva contra-hegemônica. In: LAIA, M. A.; PALEROSI, D. M.; SILVEIRA (Org.).Construindo a igualdade racial. São Paulo: Prefeitura de São Paulo, 2012.

SÃO PAULO (Estado). Secretaria da Educação. Currículo do Estado de São Paulo: Ciências Humanas e suas Tecnologias. São Paulo: SE, . 2012. 
VALIM, K. A África na sala de aula: seus objetivos, perspectivas e desafios. Revista História em Curso, Belo Horizonte, MG, v. 2, n. 2, p. 33-50, 2012.

Recebido para publicação em 10/08/2018

Revisado em 15/08/2018

Aceito em 17/09/2018 